\title{
Effects of interaction between Escherichia coli verotoxin and lipopolysaccharide on cytokine induction and lethality in mice
}

\author{
KURI SUZUKI, KAZUHIRO TATEDA*, TETSUYA MATSUMOTO*, FUMIO GONDAIRA†, \\ SHIROU TSUJIMOTO
}

First Department of Urology and Departments of * Microbiology and \$Pathology, Toho University School of Medicine, 5-21-16 Ohmorinishi, Ohtaku, Tokyo 143-8540 and †Denkaseiken Co. Ltd. Gosenshi, Minamimotomachi 1-2-2, Niigata 959-16, Japan

\begin{abstract}
In Escherichia coli 0157 infections, verotoxins (VT) play a critical role in causing the disease, although other factors such as lipopolysaccharide (LPS) and inflammatory cytokines may affect the progression and course of the disease. The present study examined the roles of VT and LPS in induction of serum cytokines and lethality in mice. LD50 of VT2 (13 ng) was c. $10^{4}$-fold smaller than that of LPS (400 $\left.\mu \mathrm{g}\right)$. Although the lethal toxicity of these toxins was examined in several experimental conditions, such as VT2 $(5,10,20,40 \mathrm{ng} /$ mouse) alone or in combination with LPS $(100 \mu \mathrm{g} / \mathrm{mouse})$ at various times $(-2$ days to +2 days), no evidence of synergy was observed. VT2 did not augment LPS-induced tumour necrosis factor- $\alpha$ (TNF- $\alpha$ ) or interleukin-6 production, and conversely suppressed TNF- $\alpha$ production when it was injected 2 days before LPS challenge. The data failed to indicate either synergic or additive effects of VT and LPS on cytokine production or lethality in mice. In contrast, antagonistic interactions were clearly observed in cytokine production in certain conditions. The results suggested that these toxins may be co-operatively involved in the pathology of VT-related diseases, but not through synergic interactions.
\end{abstract}

\section{Introduction}

Escherichia coli $\mathrm{O} 157$ is associated with outbreaks of diarrhoea, haemorrhagic colitis and haemolytic uraemic syndrome (HUS) $[1,2]$. This serotype belongs to the family of enterohaemorrhagic $E$. coli, which produces several virulence factors, such as intimin [3], haemolysins [4], lipopolysaccharide (LPS) and verotoxins (VT) [5]. In particular, the last two factors are crucial in the pathogenesis of HUS. The pro-inflammatory cytokines, tumour necrosis factor (TNF) and interleukin-1 (IL-1), have been shown to affect the severity and pathophysiology of VT-associated disease $[6,7]$.

It is well known that LPS is capable of stimulating the induction of cytokines in vitro and in vivo, whereas the activity of VT is controversial. Tesh et al. [8] reported that VT induced expression of pro-inflammatory cytokines from murine peritoneal macrophages, whereas

Received 14 Sept. 1999; revised version accepted 8 March 2000.

Corresponding author: Dr K. Tateda (e-mail: kazu@med. toho-u.ac.jp).
Harel et al. [9] showed that intraperitoneal injection of VT in mice did not induce the production of serum TNF. Several investigators have shown that TNF and IL-1 induce expression of the VT receptor (globotriacylceramide, Gb3) on human endothelial cells in vitro $[6,7]$, which may sensitise hosts to VT, although the exact interactions and co-operative roles of VT, LPS and cytokines in vitro remain to be clarified. CD-18mediated leucocyte accumulation and adherence to the endothelium was suggested to be a critical event in the development of HUS [10, 11].

The present study examined the in-vivo effects of VT and LPS on the induction of pro-inflammatory cytokines, such as TNF- $\alpha$, IL-1 and IL-6, and lethality in mice.

\section{Materials and methods}

Animals

BALB/c mice (5-6 weeks old, male, specific pathogen-free) were purchased from Shizuoka Laboratory Animal Center (Shizuoka, Japan). Mice were housed in 
groups of 10 and were provided with food and water $a d$ libitum. The experimental protocol was approved by the Ethics Review Committee for Animal Experimentation of Toho University Medical School.

\section{Toxin preparation}

Verotoxins 1 and 2 were purified from cell lysates of $E$. coli strain $87-27$ and E. coli strain Tp8, respectively, as described previously with minor modifications [12]: ammonium sulphate $60 \%$ precipitation followed by DEAE-sepharose column chromatography with a gradient elution of $0-0.4 \mathrm{M} \mathrm{NaCl}$ in $10 \mathrm{mM}$ Tris- $\mathrm{HCl}$ (pH 8.5); Q-sepharose High Performance column (Amersham Pharmacia Biotech, Uppsala, Sweden) chromatography with a gradient elution of $0-0.4 \mathrm{M}$

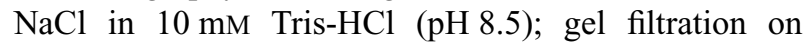

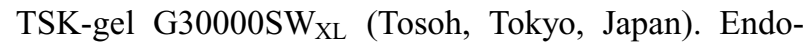
toxin content in VT2 was determined by a commercial Limulus test (Endospecy ES-6, Seikagaku, Tokyo, Japan) as $90 \mathrm{pg}$ of LPS $/ 1 \mu \mathrm{g}$ of VT2. E. coli O55:B5 LPS was purchased from Difco Laboratories (Detroit, MI, USA) and was diluted before use to the desired concentration with pyrogen-free saline.

\section{Determination of LD50 of VT2 and LPS}

Mice were inoculated intraperitoneally (i.p.) or intravenously (i.v.) with two-fold dilutions of purified VT2 (0.16-400 ng/mouse) or LPS (100-800 $\mu \mathrm{g} /$ mouse) and cumulative mortality was then monitored over the next 7 days.

\section{Effect of LPS and VT2 on mortality rate}

A protocol involving the i.p. administration of various concentrations of VT2 $(5,10,20$ and $40 \mathrm{ng})$ to mice in combination with sub-lethal LPS $(100 \mu \mathrm{g})$, which was injected i.p. $48 \mathrm{~h}$ earlier, simultaneously, 24 or $48 \mathrm{~h}$ after VT2 administration was followed. In some experiments, different doses of LPS $(100-800 \mu \mathrm{g})$ were administered simultaneously with $0.8 \mathrm{ng}$ of $\mathrm{VT} 2 /$ mouse and changes in the mortality rate were examined.

\section{Serum pro-inflammatory cytokines}

Mice $(\mathrm{n}=5)$ were inoculated i.p. with $100 \mu \mathrm{g}$ of LPS or $20 \mathrm{ng}$ of VT2 alone or in combination with LPS. Blood samples were collected by cardiac puncture at 0 , $1.5,3,6,24,48 \mathrm{~h}$ after inoculation. Blood was allowed to clot at $4^{\circ} \mathrm{C}$ for $2 \mathrm{~h}$ and centrifuged to obtain serum samples that were stored in divided volumes at $-80^{\circ} \mathrm{C}$ before being used for cytokine assays. The concentrations of TNF- $\alpha$, IL- 6 and IL- $\beta$ in sera were determined with commercially available ELISA kits (Biosource International, Camarillo, CA, USA).

\section{Histological studies}

Mice were inoculated i.p. with $100 \mathrm{ng}$ (c. $10 \times$ LD50) of purified VT2 or $100 \mu \mathrm{g}$ of LPS alone or in a combination of the two. They were then killed at 1, 2, or 3 days after injection. The colon, liver and kidneys were surgically removed and examined for pathological changes. Tissues were then fixed in formalin $10 \%$ and routinely processed. Sections of paraffin-embedded tissues were stained with haematoxylineosin and examined by light microscopy.

\section{Statistical analysis}

Student's $t$ test was used to compare the mean values of different groups and the $\chi^{2}$ test was used to compare survival rates; $\mathrm{p}<5 \%$ was accepted as statistically significant.

\section{Results}

\section{LD50 of $V T_{2}$ and LPS}

Groups of five mice were inoculated i.p. or i.v. with two-fold dilutions of purified $\mathrm{VT}_{1}, \mathrm{VT}_{2}$ or LPS. The LD50s of VT2 (i.v. and i.p.) were c. $1.5 \mathrm{ng}$ and $13 \mathrm{ng} /$ mouse, respectively (Fig. 1). The LD50 of LPS administered i.p. was estimated to be $c .400 \mu \mathrm{g}$. These data indicated that VT2 was c. $10^{4}$-fold more lethal than LPS.

Changes in lethality following injection with VT2 in combination with sub-lethal LPS at different time intervals

Treatment of mice with 20 or $40 \mathrm{ng}$ of VT2 was associated with a $>90 \%$ mortality rate even in the absence of LPS administration (Fig. 2). Although higher mortality rates were demonstrated in groups of mice treated with $10 \mathrm{ng}$ of VT2 in combination with LPS than that with VT2 alone, these differences were not significant.

\section{Histological examination}

In mice treated with VT2 (100 ng), nuclear vesiculation and cytoplasmic vacuolation in kidney tubules were noted after 3 days, whereas no apparent changes were observed earlier (Fig. 3a and b). No pathological changes were seen in the colon, small intestine or liver.

\section{Serum cytokine levels}

Although the peak concentrations of TNF- $\alpha$ and IL-6 were noted, at 1.5 and $3 \mathrm{~h}$, respectively, after administration of a sub-lethal dose of LPS, injection of the lethal dose of VT2 did not induce detectable levels of these cytokines (Fig. 4). Moreover, the concentration of these cytokines was not different in mice treated with LPS and LPS + VT2. Only small amounts of IL- $1 \beta$ 


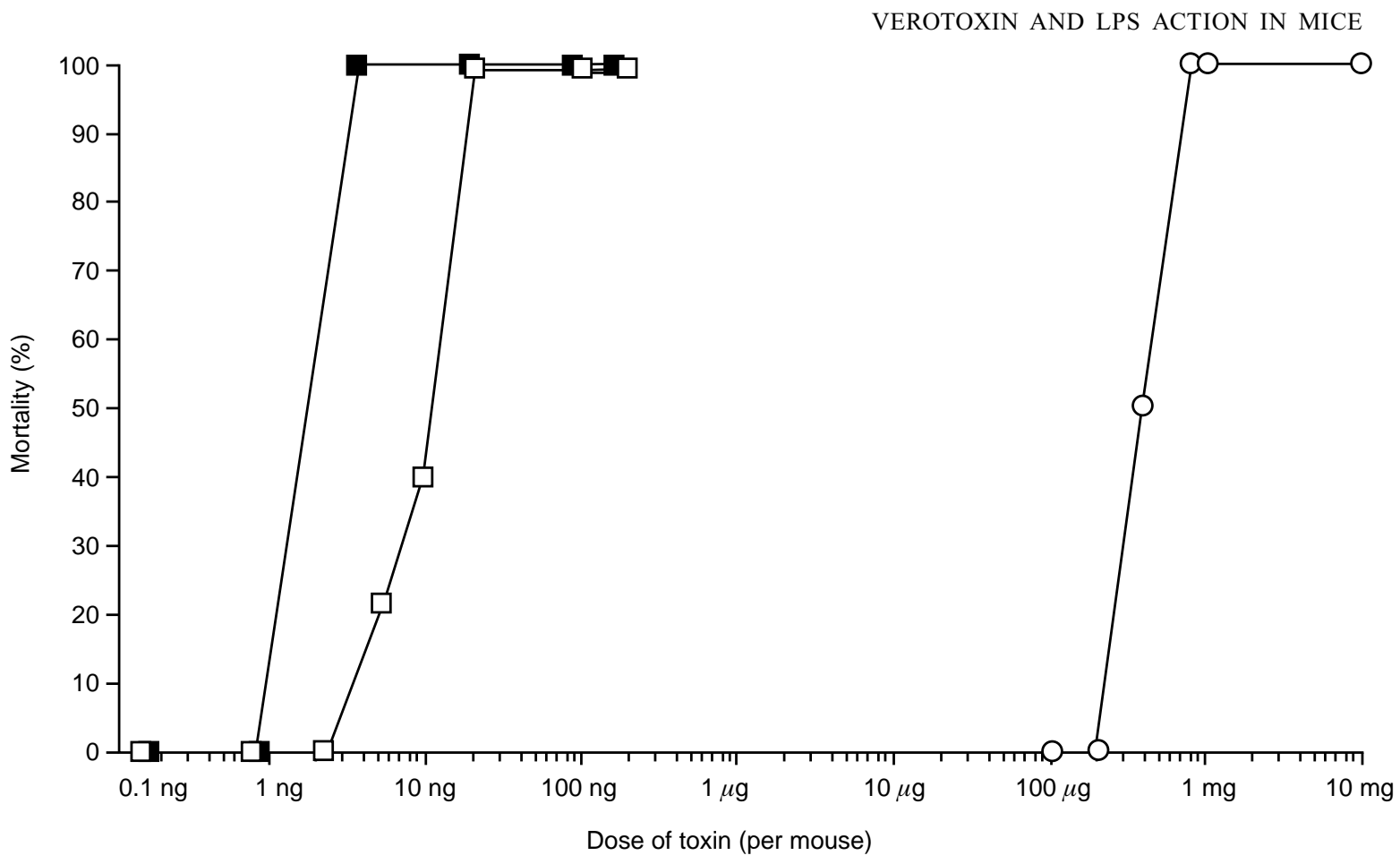

Fig. 1. Comparison of lethal toxicity of VT2 ( $\square$, i.v.; $\square$, i.p.;) and LPS (○, i.p.) for mice.

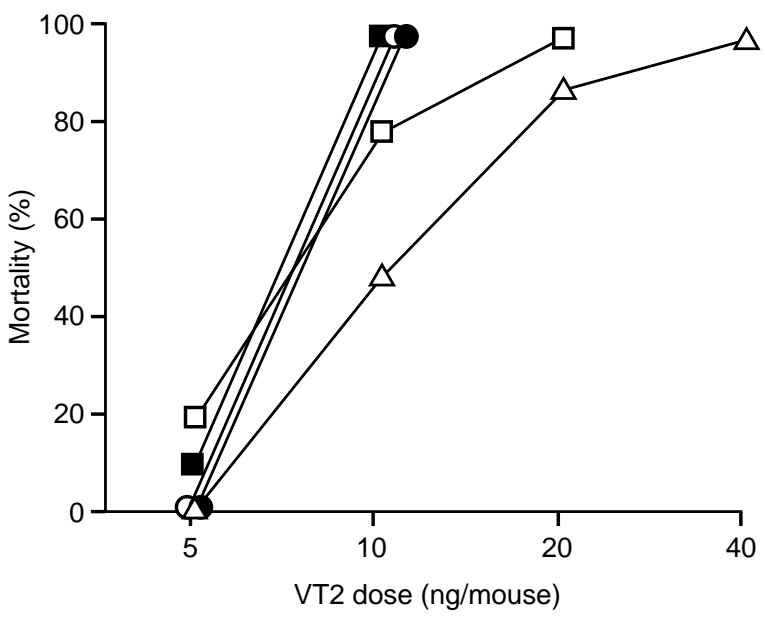

Fig. 2. Effect of a sub-lethal dose of LPS $(100 \mu \mathrm{g})$ administered at different times on mouse lethality induced by VT2: $\bigcirc-\mathrm{O}$, LPS $48 \mathrm{~h}$ before VT2; LPS simultaneously with VT2; $\square-\square$, LPS $24 \mathrm{~h}$ after VT2; - $\mathbf{- \square}$, LPS $48 \mathrm{~h}$ after VT2; $\triangle-\triangle$, VT2 alone.

were detected between 3 and $6 \mathrm{~h}$, and significant differences were not demonstrated among the three groups. The study also investigated the effects of VT2 on LPS-induced TNF- $\alpha$ production. When a higher dose of VT2 (100 ng) was administered simultaneously with LPS, a slight suppression of TNF- $\alpha$ production was observed (Fig. 5). Interestingly, a marked inhibition of LPS-induced TNF- $\alpha$ production was noted in mice treated with VT2 $48 \mathrm{~h}$ before induction of LPS.

\section{Discussion}

The data showed that VT was highly toxic for mice. The LD50 of VT2 was $c$. $10^{4}$-fold higher than that of LPS. Such toxicity was similar to the results described in previous reports [13]. In the present study, LPS contamination in VT2 was minimal (only $90 \mathrm{pg} / 1 \mu \mathrm{g}$ of VT2). However, great care must be taken when examining cytokine induction in vivo by bacterial products or components, because LPS is one of the most potent inducers of inflammatory cytokines. Interestingly, no induction of IL-1, IL-6 or TNF- $\alpha$ was observed with $20 \mathrm{ng}$ of VT2, which was 10 times higher than the LD50 for this toxin. These data strongly suggest that VT2 does not induce these inflammatory cytokines.

Several clinical studies have demonstrated a low frequency of patients with HUS who have high serum levels of TNF- $\alpha$. Inward et al. [14] reported that two of 19 children with VT-producing $E$. coli infection complicated with HUS were positive for serum TNF$\alpha$. Furthermore, van de Kar et al. [15] showed no increase in plasma TNF- $\alpha$ in HUS patients compared to healthy controls, and Fitzpatrick et al. [16] found TNF- $\alpha$ present in the plasma of only one of 16 patients with HUS. The data on serum cytokines in mice from the present study were largely consistent with these clinical data. Recently, the molecular basis for induction and localisation of TNF- $\alpha$ by VT was investigated in an elegant experiment in mice bearing a chloramphenicol acetyltransferase (CAT) reporter gene that indicates TNF- $\alpha$ synthesis [9]. After injection of VT in 

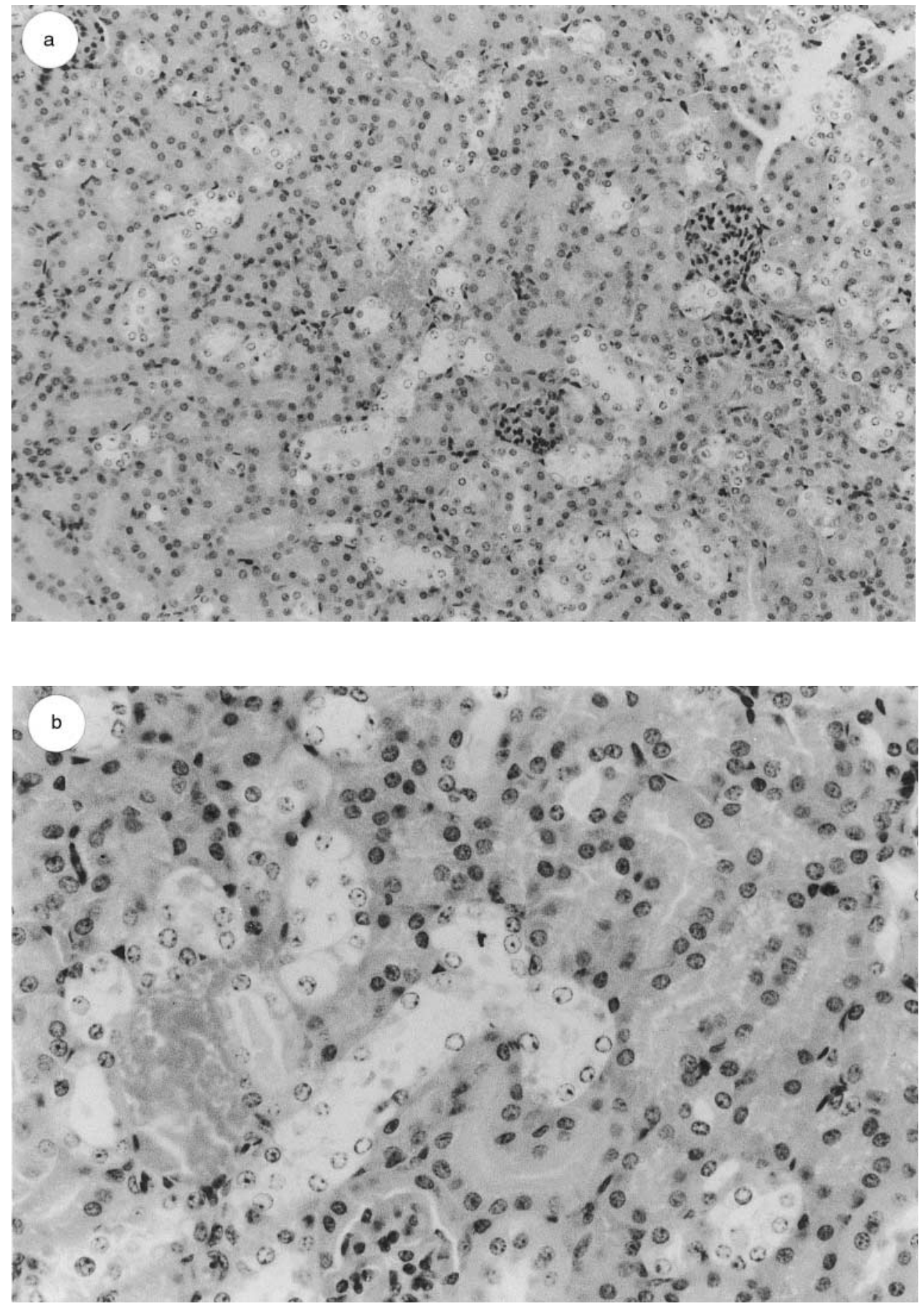

Fig. 3. Pathological characteristics in kidneys of mice given VT2 (100 ng). Nuclear vesiculation and cytoplasmic vacuolation in kidney tubules were noted at 3 days. (a) $\times 100$; (b) $\times 400$.

these mice, CAT activity was induced selectively in the kidney. These data demonstrated the distinct potential of VT to upregulate TNF- $\alpha$ gene expression in the kidney, which fits well with the unique sensitivity of the kidney to microvascular damage in HUS, although specific expression of the TNF- $\alpha$ gene in the human kidney has not been investigated.

Simultaneous administration of VT2 and LPS did not result in a synergic effect with regard to serum cytokine levels. In contrast, a marked inhibition of LPS-induced TNF- $\alpha$ production occurred when mice were treated with VT2 $48 \mathrm{~h}$ before LPS challenge. The molecular mode of action of VT has been studied extensively [5]. VT inhibits protein synthesis in eukaryotic cells by inactivating $60 \mathrm{~S}$ ribosomal subunits, resulting in the inhibition of elongation factor-1dependent aminoacyl-tRNA binding to 60S ribosomal subunits. It is most likely that the lethal dose of VT inhibits the synthesis of several proteins, which may 
a

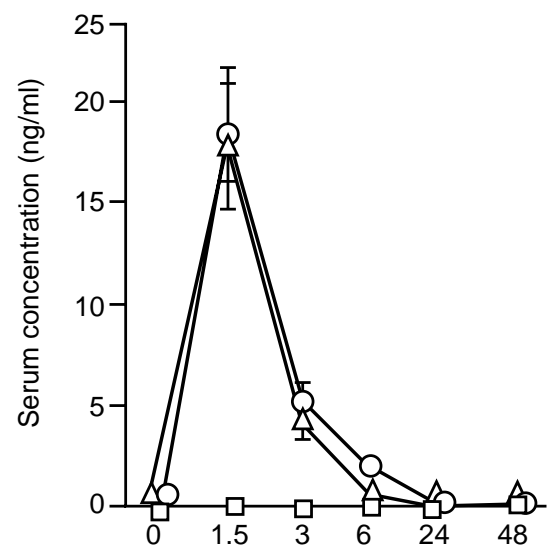

b

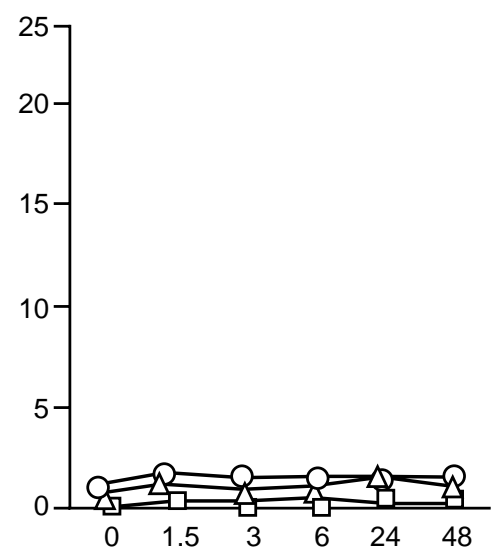

Time (h) after administration of toxin
C

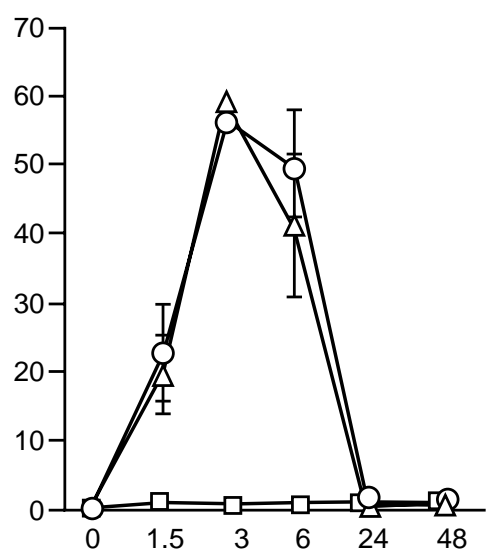

Fig. 4. Serum TNF- $\alpha$ (a), IL-1 $\beta$ (b) and IL-6 (c) levels after administration of VT2 (20 ng/mouse, $\square$ ), LPS $(100 \mu \mathrm{g} /$ mouse, $\bigcirc)$ or VT2 plus LPS $(\triangle)$.

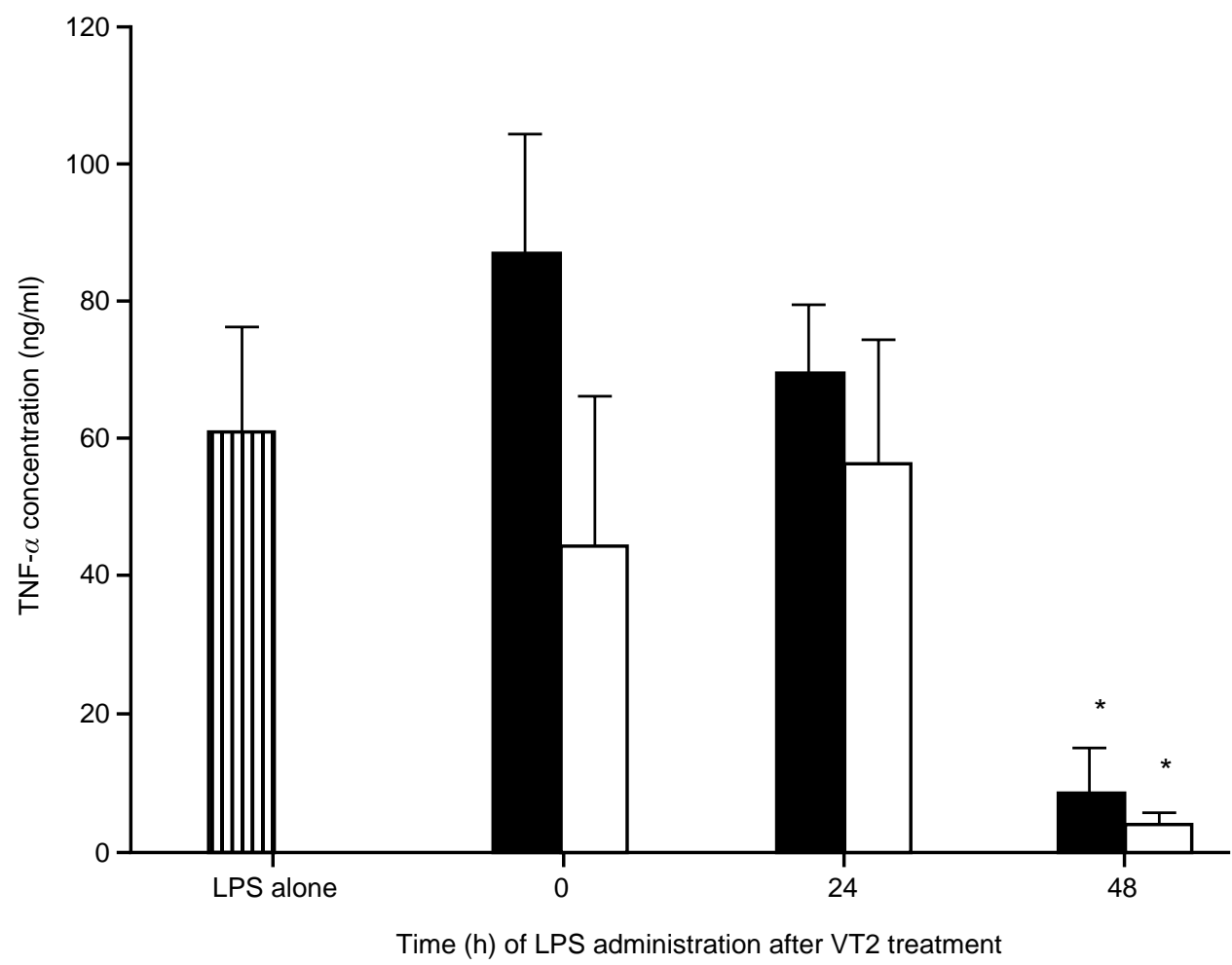

Fig. 5. Serum TNF- $\alpha$ concentrations after administration of VT2 and LPS at various times: 回, LPS (100 $\mu \mathrm{g} / \mathrm{mouse})$; 口, VT2 (20 ng/mouse) + LPS; $\square$, VT2 (100 mg/mouse) + LPS. Serum TNF- $\alpha$ levels were measured $1.5 \mathrm{~h}$ after administration of LPS. ${ }^{*} \mathrm{p}<0.01$, compared with LPS alone.

include factors responsible for the expression of TNF- $\alpha$.

The present study examined changes in the mortality rates of mice under several experimental conditions, in which various concentrations of VT were administered in combination with sub-lethal doses of LPS at various times, but significant effects of the combination were not observed. In LPS-responder $(\mathrm{C} 3 \mathrm{H} / \mathrm{HeN})$ and LPSnon-respondent mice $(\mathrm{C} 3 \mathrm{H} / \mathrm{HeJ})$, Karpman et al. [17] reported different courses of disease with intragastri- cally inoculated VT-producing E. coli. In this regard, Harel et al. [9] reported that VT sensitised $\mathrm{C} 3 \mathrm{H} / \mathrm{HeN}$ mice to the lethal effect of LPS and TNF, whereas pretreatment with either LPS or TNF did not noticeably sensitise the mice to the lethal effect of VT. Barrett et al. [18] also reported that pre-treatment of $\mathrm{C} 3 \mathrm{H} / \mathrm{HeN}$ mice with LPS protected the animals from challenge with an LD50 but not an LD100 of VT. On the other hand, LPS enhanced the lethal effect of VT when it was administered at 8 or $24 \mathrm{~h}$ but not 0 or $72 \mathrm{~h}$ after VT challenge. However, these effects were relatively minor 
compared with in-vitro results, where the cytotoxic activity of VT was markedly enhanced by up to $6 \log _{10}$ orders by pro-inflammatory cytokines $[6,8]$. It is difficult to explain the discrepancy between previous and present data, but possible reasons may include differences in the strain of mice used, preparation of toxins and experimental conditions.

The characteristic features of renal histology in human patients with HUS include thrombotic micro-angiopathy in the glomeruli and cortical tubular necrosis [19]. Glomerular damage is thought to be a consequence of the cytotoxic effect of VT on capillary endothelial cells. In the present study, the pathological changes in the kidneys of mice treated with lethal doses of VT were observed mainly in tubules (nuclear vesiculation and cytoplasmic vacuolation), but not in glomeruli. These observations were quite similar to those described by other investigators [20]. The lack of glomerular damage may be due to the absence of a functional receptor specific for VT. These results indicated that the pathological states induced by VT in mice are clearly different from those in man. Accordingly, care must be taken when considering the relevance of results obtained from a mouse model of enterohaemorrhagic $E$. coli infection to the human disease.

We thank Nobuhisa Ishii for critically reading the manuscript and helpful suggestions.

\section{References}

1. Karmali MA, Petric M, Lim C, Fleming PC, Arbus GS, Lior $\mathrm{H}$. The association between idiopathic hemolytic uremic syndrome and infection by verotoxin-producing Escherichia coli. J Infect Dis 1985; 151: 775-782.

2. Wells JG, Davis BR, Wachsmuth IK et al. Laboratory investigation of hemorrhagic colitis outbreaks associated with a rare Escherichia coli serotype. J Clin Microbiol 1983; 18: $512-520$.

3. Jerse AE, Yu J, Tall BD, Kaper JB. A genetic locus of enteropathogenic Escherichia coli necessary for the production of attaching and effacing lesions on tissue culture cells. Proc Natl Acad Sci USA 1990; 87: 7839-7843.

4. Schmidt H, Beutin L, Karch H. Molecular analysis of the plasmid-encoded hemolysin of Escherichia coli $\mathrm{O} 157: \mathrm{H} 7$ strain EDL 933. Infect Immun 1995; 63: 1055-1061.
5. O'Brien AD, Holmes RK. Shiga and Shiga-like toxins. Microbiol Rev 1987; 51: 206-220.

6. Louise CB, Obrig TG. Shiga toxin-associated hemolytic-uremic syndrome: combined cytotoxic effects of shiga toxin, interleukin-1 $\beta$, and tumor necrosis factor alpha on human vascular endothelial cells in vitro. Infect Immun 1991; 59: 4173-4179.

7. van de Kar NCAJ, Monnens LAH, Karmali MA, van Hinsbergh VWM. Tumor necrosis factor and interleukin-1 induce expression of the verocytotoxin receptor globotriaosylceramide on human endothelial cell: implications for the pathogenesis of the hemolytic uremic syndrome. Blood 1992; 80: $2755-2764$.

8. Tesh VL, Ramegowda B, Samuel JE. Purified shiga-like toxins induce expression of proinflammatory cytokines from murine peritoneal macrophages. Infect Immun 1994; 62: 5085-5094.

9. Harel Y, Silva M, Giroir B, Weinberg A, Cleary TB, Beutler B. A reporter transgene indicates renal-specific induction of tumor necrosis factor (TNF) by shiga-like toxin. Possible involvement of TNF in hemolytic uremic syndrome. J Clin Invest 1993; 92: 2110-2116.

10. Elliott E, Li Z, Bell C et al. Modulation of host response to Escherichia coli $\mathrm{O} 157: \mathrm{H} 7$ infection by anti-CD18 antibody in rabbits. Gastroenterology 1994; 106: 1554-1561.

11. Forsyth KD, Simpson AC, Fitzpatrick MM, Barratt TM, Levinsky RJ. Neutrophil-mediated endothelial injury in haemolytic uremic syndrome. Lancet 1989; 2: 411-414.

12. Noda M, Yutsudo T, Nakabayashi N, Hirayama T, Takeda Y. Purification and some properties of Shiga-like toxin from Escherichia coli $\mathrm{O} 157: \mathrm{H} 7$ that is immunologically identical to Shiga toxin. Microbial Pathogenesis 1987; 2: 339-349.

13. Takeda Y, Kuranzono H, Yamasaki S. Vero toxins (shiga-like toxins) produced by enterohemorrhagic Escherichia coli (verocytotoxin-producing E. coli). Microbiol Immunol 1993; 37: 591-599.

14. Inward CD, Varagunam M, Adu D, Milford DV, Taylor CM. Cytokines in haemolytic uraemic syndrome associated with verocytotoxin-producing Escherichia coli infection. Arch Dis Child 1997; 77: 145-147.

15. van de Kar NCAJ, Sauerwein RW, Demacker PNM, Grau GE, van Hinsbergh VWM, Monnens LAH. Plasma cytokine levels in hemolytic uremic syndrome. Nephron 1995; 71: 309-313.

16. Fitzpatrick MM, Shah V, Trompeter RS, Dillon MJ, Barratt TM. Interleukin-8 and polymorphoneutrophil leucocyte activation hemolytic uremic syndrome of childhood. Kidney Int 1992; 42: 951-956.

17. Karpman D, Connell H, Svensson M, Scheutz F, Alm P, Svanborg C. The role of lipopolysaccharide and shiga-like toxin in a mouse model of Escherichia coli O157:H7 infection. J Infect Dis 1997; 175: 611-620.

18. Barrett TJ, Potter ME, Wachsmuth IK. Bacterial endotoxin both enhances and inhibits the toxicity of shiga-like toxin II in rabbits and mice. Infect Immun 1989; 57: 3434-3437.

19. Richardson SE, Karmali MA, Becker LE, Smith CR. The histopathology of the hemolytic uremic syndrome associated with verotoxin-producing Escherichia coli infections. Hum Pathol 1988; 19: 1102-1108.

20. Wadolkowski EA, Burris JA, O'Brien AD. Mouse model for colonization and disease caused by enterohemorrhagic Escherichia coli O157:H7. Infect Immun 1990; 58: 2438-2445. 